\title{
Analysis of opioids in postmortem urine samples by dispersive liquid-liquid microextraction and high performance liquid chromatography with photo diode array detection
}

\author{
Elham Alahyari ${ }^{1}$, Mehrdad Setareh $^{2,3}$, Ahmad Shekari $^{2,3}$, Gholamreza Roozbehani $^{2,3}$ and Kambiz Soltaninejad ${ }^{3 *}$ (D)
}

\begin{abstract}
Background: Opioids abuse and related deaths are increasing in the world. Therefore, the design of new analytical methods for detection of opioids in biological samples is necessary for clinical and forensic settings.

Methods: In this study, dispersive liquid-liquid microextraction (DLLME) combined with high-performance liquid chromatography with photo diode array detector (HPLC-PDA), as a new and sensitive method were examined for the extraction and determination of morphine, codeine and methadone in postmortem urine samples. Effective factors on DLLME were optimized. The extracts were analyzed by HPLC-PDA using a Eurospher ${ }^{\circledR} \mathrm{C}_{18}$ column (250 $\mathrm{mm} \times 4.6 \mathrm{~mm}$, particle size: $5 \mu \mathrm{m})$.

Results: The volumes of chloroform as the extraction solvent and acetone as the dispersive solvent were selected $300 \mu \mathrm{l}$ and $500 \mu$ l, respectively. The optimum pH 9.8 and extraction time was 0.5 min were selected. Under optimum condition, the enrichment factor and the recovery of morphine, codeine, and methadone spiked into postmortem urine samples were in the range of 175-215.8 and 87.5-107.9\%, respectively. Calibration curves for each analyte are linear in the range of $0.5-100 \mathrm{\mu g} \mathrm{ml}^{-1}$. Limit of detection (LOD) for the analytes was in the range of $10-25 \mathrm{\mu g} \mathrm{I}^{-1}$. Finally, the proposed method was successfully applied to 50 postmortem urine samples for determination of the opioids.

Conclusions: The proposed method is an easy, fast, low cost and efficient for the extraction and determination of opioids in postmortem urine samples and should be considered as analytical method for determination of opioids in forensic and clinical toxicology labs.
\end{abstract}

Keywords: Opioids, Urine, Postmortem, DLLME, HPLC-PDA

\section{Background}

In recent years, substance abuse has been widely spread in the world and has social, economic, cultural and political dimensions in the society and considered as a major health threat (UNODC 2016). Opioids are a class of analgesics commonly used in clinical medicine for treatment of moderate and sever pain (Gergov et al. 2009; Pathan and Williams 2012). Also, they have the high potential for abuse

\footnotetext{
*Correspondence: kamsoltaninejad@gmail.com

${ }^{3}$ Department of Forensic Toxicology, Legal Medicine Research Center, Legal Medicine Organization, Tehran 1114795113, Iran

Full list of author information is available at the end of the article
}

(UNODC 2016). Therefore, analysis of the opioids in biological samples has been considered as an important issue in the forensic and clinical toxicology (Gergov et al. 2009; Shamsipur and Fattahi 2011). The determination of abused drugs in postmortem samples can provide some special challenges in comparison with clinical samples (Drummer 2004). The variety and quality of the biological samples such as decomposed tissues, instability and degradation of drugs of abuse in the postmortem conditions and drug redistribution are the some special features in analysis of drugs in postmortem forensic toxicology (Drummer 2004). Furthermore, the development of new analytical 
methods for the qualitative and quantitative analysis of opioids in postmortem biological samples is an important concern in the forensic toxicology (Drummer 2004). A fast, easy and effective method for sample preparation is a key role for achieving to the better analytical procedures. Some traditional analytical techniques such as liquid-liquid extraction (LLE) and solid-phase extraction (SPE) have been developed for extraction and determination of drugs including opioids in biological specimens (Wey and Thorman 2001; Whittington and Kharasch 2003; Mabuchi et al. 2004). There are some limitations on using of these methods of sample preparation. LLE method is time-consuming and requires the use of large volumes of high purity and toxic organic solvents. The SPE is a method with relatively good efficacy, but it is relatively time-consuming for some long processes such as the washing and evaporation of the solvents. Also, in some cases, the method recovery is not enough for trace analysis (Shamsipur and Fattahi 2011). Therefore, the development of rapid, easy and environment- friendly analytical methods is encouraged.

Recently, microextraction procedures are the most effective sample preparation methods prior analysis. For example, liquid-phase microextraction (LPME) was successfully used for extraction of analytes from aqueous samples (Jeannot and Cantwell 1996; He and Lee 1997). Hollow fiber LPME (HF-LPME) is another easy and low-cost sample preparation method in order to extraction of analytes from complex samples (Shen and Lee 2002; Lee et al. 2008; Saraji et al. 2011). The combination of ultrasound with microextraction and solvent drop solidification (LPME-SFO) are the two examples of developed methods based on microextraction (Leong and Huang 2008; Ma et al. 2009; Cheng et al. 2011; Zhang and Lee 2012).

Dispersive liquid-liquid microextraction (DLLME) is another type of microextraction method that consists of a trinary system of solvents including a high-density and water- immiscible extraction solvent (extractant), a dispersive solvent highly miscible with the extraction solvent and aqueous sample, and an aqueous sample (Rezaee et al. 2006). The method based on the formation of very small droplets of extraction solvent in the sample solution after injection of extractant and dispersive solvent into aqueous sample (Shamsipur and Fattahi 2011). The large contact surface area between the extraction solvent and aqueous sample forms a cloudy mixture. This phenomenon facilitates a rapid equilibration. When the cloudy solution is centrifuged, the extractant forms the sediment phase and removed with a microsyringe for later analysis (Yan and Wang 2013; Saraji and Boroujeni 2014).

The DLLME is a simple, fast, efficient, environmentallyfriendly and economic method for sample preparation (Rezaee et al. 2006; Nagaraju and Huang 2007; Shamsipur and Fattahi 2011). It has been used for various types of biological matrices ( $\mathrm{Li}$ et al. 2008; Xiong et al. 2009;
Mashayekhi et al. 2010; Rezaee et al. 2010a; Rezaee et al. 2010b; Fernández et al. 2013). DLLME could be combined with a variety of chromatography techniques such as Gas chromatography- Mass Spectrometry (GC-MS) (Leong and Huang 2008; Meng et al. 2015), High Performance Liquid Chromatography (HPLC) (Ahmadi-Jouibari et al. 2013; Fernández et al. 2015) and capillary electrophoresis (Kohler et al. 2013).

Although, there are few studies about the analysis of opium alkaloids and opioids drugs in clinical biological samples (Wey and Thorman 2001; Whittington and Kharasch 2003; Saraji et al. 2011; Shamsipur and Fattahi 2011; Ranjbari et al. 2012; Ahmadi-Jouibari et al. 2013), but there are scant data about the analysis of opioids by DLLME-HPLC-PDA in postmortem urine samples. Therefore, in this study, we optimized a DLLME-HPLCPAD for the extraction and determination of morphine, codeine, and methadone in postmortem urine samples.

\section{Methods}

\section{Chemicals}

Standard morphine, codeine and methadone were obtained from Darou Pakhsh Pharmaceutical Co. (Tehran, Iran). HPLC grade solvents including acetonitrile, methanol, acetone, chloroform, water, phosphoric acid, potassium dihydrogen phosphate, sodium carbonate were purchased from Merck Co. (Darmstadt, Germany). To prepare the $0.05 \mathrm{M}$ phosphate buffer, $16.65 \mathrm{~g}$ potassium dihydrogen phosphate was dissolved in $2.5 \mathrm{l}$ of HPLC-grade water and the $\mathrm{pH}$ of the buffer in the mobile phase was adjusted to $\mathrm{pH} 2.3$ using phosphoric acid $85 \% w / v$. Stock standard solution with concentration level $1 \mathrm{mg} \mathrm{ml}^{-1}$ were prepared for morphine, codeine and methadone in methanol was prepared. Working standards were made by dilution of stock solution to final concentrations in urine. All solutions were stored at $4{ }^{\circ} \mathrm{C}$.

\section{Instrumentation}

An HPLC system including pump (Smartline, Model 1050) and Smartline PDA 2850 (multi wavelength) detector with RP column Eurospher ${ }^{\circ}(250 \mathrm{~mm} \times$ $4.6 \mathrm{~mm}$, particle size: $5 \mu \mathrm{m}$ ) was used in this study. Data processing was performed with ChromGate software (version 3.1.7), all from Knauer Co. (Berlin, Germany). The mobile phase consisted of acetonitrile (A) and $0.05 \mathrm{M}$ phosphate buffer at $\mathrm{pH} 2.3$ (B). Buffer and the mobile phase flow rate of $1 \mathrm{ml} \mathrm{min}^{-1}$ was used in gradient elution mode: $0-7 \mathrm{~min}, \mathrm{~A} \% 10$ and $\mathrm{B} \% 90 ; 7-8 \mathrm{~min}, \mathrm{~A} \% 20$ and $\mathrm{B} \% 80 ; 8-15 \mathrm{~min}$, $\mathrm{A} \% 20$ and $\mathrm{B} \%$ 80; $15-16 \mathrm{~min}, \mathrm{~A} \% 37$ and $\mathrm{B} \%$ 63; 16-40 min, A\% 37 and B\% 63; 40-45 min, A\% 10 and $\mathrm{B} \% 90$. 


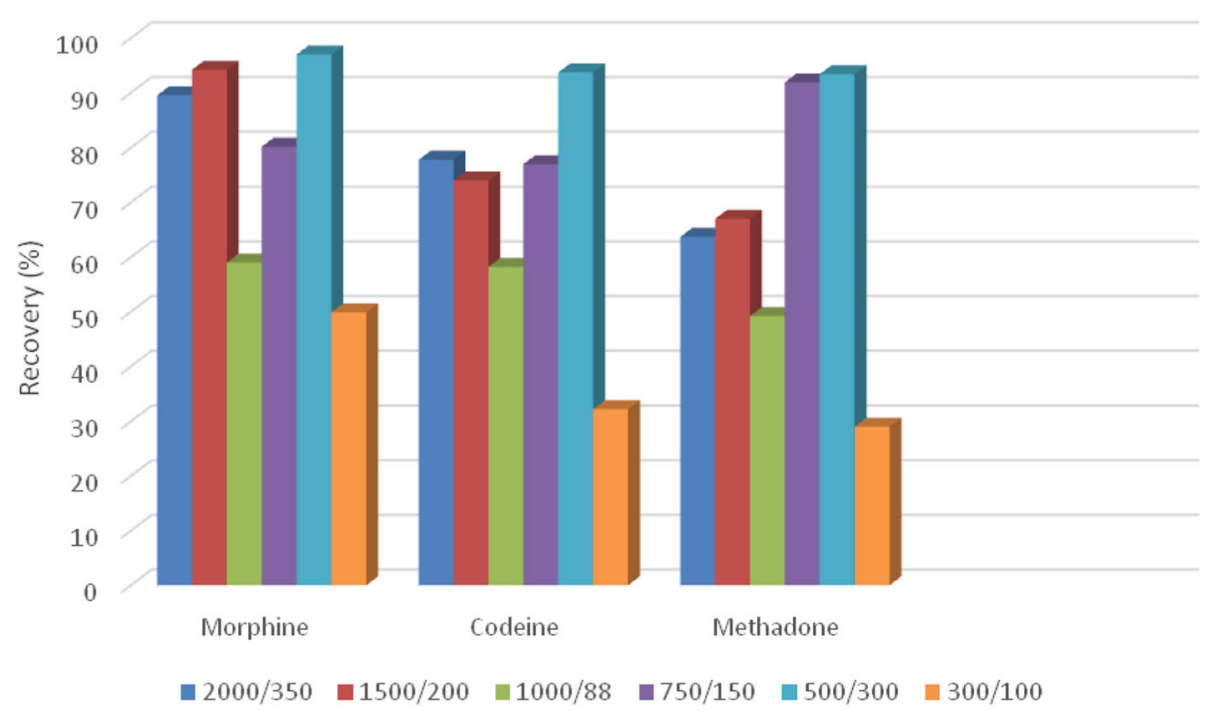

Fig. 1 Effect of the volume of acetone as disperser solvent and the volume of chloroform as extraction solvent on the recovery of morphine, codeine and methadone. Extraction conditions: sample volume, $5 \mathrm{ml}$, volumes of acetone: 300, 500, 750, 1000, 1500 and $2000 \mu \mathrm{l}$ with containing 100, 300, 150, 88, 200 and $350 \mu \mathrm{l}$ of chloroform, respectively, pH 9.8; extraction time, $0.5 \mathrm{~min}$ and the spiked concentration of morphine, codeine and methadone was $10 \mu \mathrm{gml}^{-1}$

\section{Extraction of opioids in postmortem urine samples with} DLLME

Blank postmortem urine samples (drug-free) were obtained during the autopsy of cadavers without any drug abuse/poisoning history. The blank samples tested by routine postmortem toxicological analysis (Thin layer chromatography (TLC) for screening and GC-MS for confirmation). Also, postmortem urine samples were collected from the cadavers with opioids abuse/poisoning which have been transferred to forensic toxicology laboratory of Zanjan legal medicine center (Zanjan, Iran). The samples were stored at $-20{ }^{\circ} \mathrm{C}$ until analysis. The ethical committee of the Legal Medicine Research Center (Tehran-Iran) approved this project (Grant No. 20726).

Initially, the frozen urine samples were thawed at room temperature and then were centrifuged for $15 \mathrm{~min}$ at $4000 \mathrm{rpm}$. The supernatant was transferred into clean $15 \mathrm{ml}$ conical test tube and filtrated by a $0.22 \mu \mathrm{m}$ filter, then $2 \mathrm{ml}$ of the sample was transferred to a $10 \mathrm{ml}$ test tube and $3 \mathrm{ml}$ distilled water was added (to reduce matrix effects).

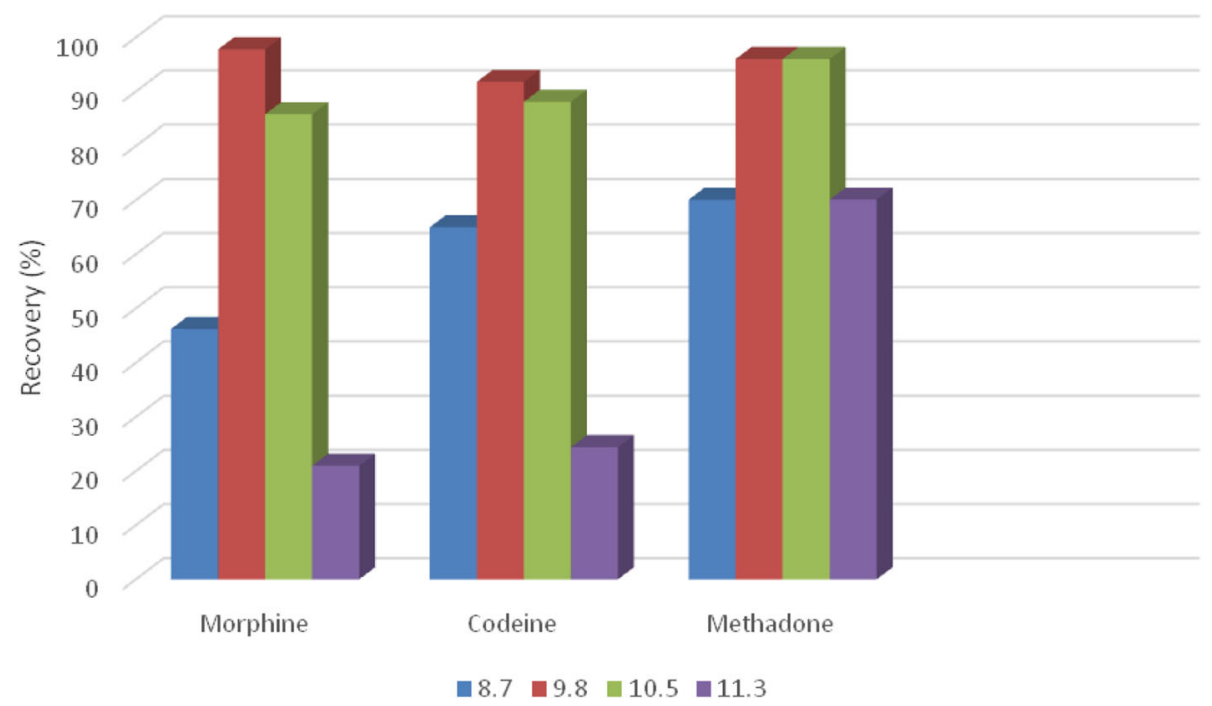

Fig. 2 Effects of the $\mathrm{pH}$ on the recovery of morphine, codeine and methadone from postmortem urine samples. Extraction conditions: sample volume: $5 \mathrm{ml}$, volume of acetone: $500 \mu \mathrm{l}$ and volume of chloroform: $300 \mu \mathrm{l}$, extraction time: $0.5 \mathrm{~min}$ and the spiked concentration of morphine, codeine and methadone was $10 \mathrm{\mu g} \mathrm{ml}^{-1}$ 


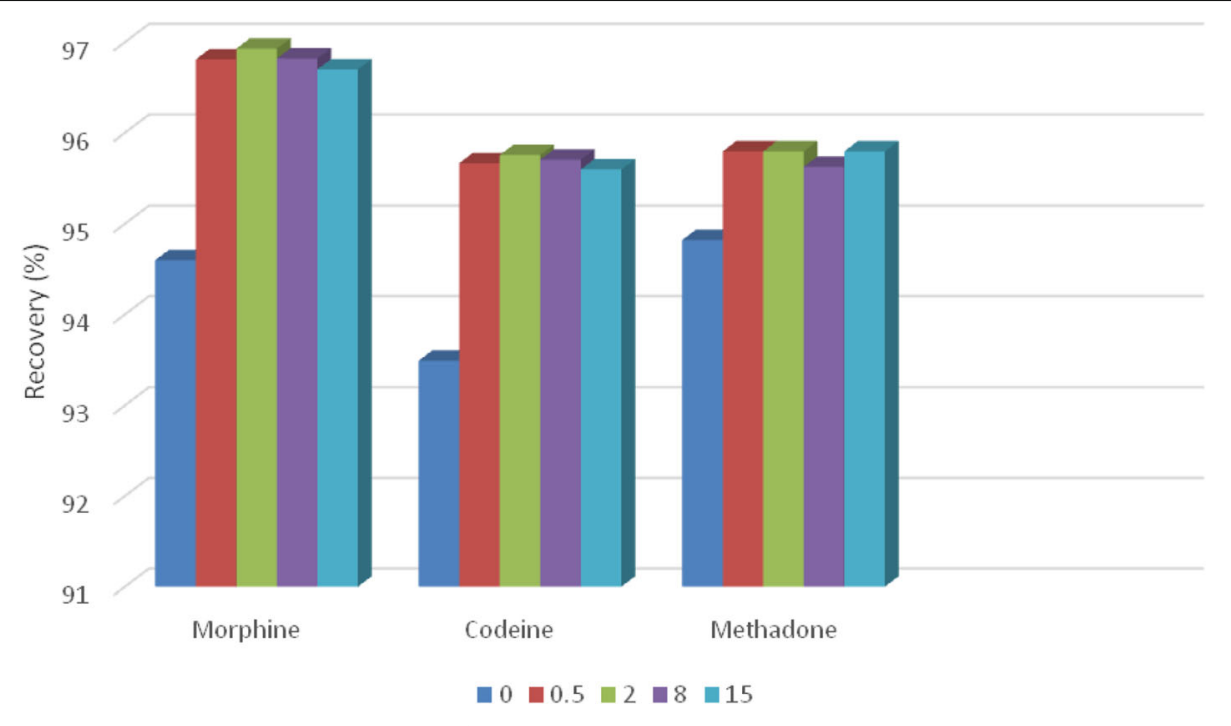

Fig. 3 Effect of extraction time (minutes) on the recovery of morphine, codeine and methadone. Extraction conditions: sample volume: $5 \mathrm{ml}$, volume of acetone: $500 \mu \mathrm{l}$ and volume of chloroform: $300 \mu \mathrm{l}, \mathrm{pH}$ 9.8, the spiked concentration of morphine, codeine and methadone were $10 \mu \mathrm{gl}^{-1}$

For the DLLME, an aliquot of $5 \mathrm{ml}$ samples containing 2, 10 and $30 \mu \mathrm{g} \mathrm{ml}^{-1}$ of morphine, codeine and methadone were prepared and $\mathrm{pH}$ of the samples was adjusted at 9.8 by adding appropriate amounts of sodium carbonate $(10 \% w / v) .300 \mu \mathrm{l}$ of chloroform (extraction solvent) and $500 \mu \mathrm{l}$ of acetone (disperser solvent) were mixed well together then this mixture was injected rapidly by using a $2 \mathrm{ml}$ syringe into the sample solution and a cloudy mixture has been formed. In this step, the analytes were extracted into the tiny droplet of chloroform, in a very short time. Then the samples were vortexed for $30 \mathrm{~s}$ and centrifuged at $4000 \mathrm{rpm}$ for $10 \mathrm{~min}$. After the centrifugation, fine droplets of extraction solvent were sediment at the bottom of the test tube. The sediment phase removed with a $100 \mu \mathrm{l}$ microsyringe (Hamilton, USA) and replaced to a $1 \mathrm{ml}$ glass vial. After evaporation of the solvent under stream of nitrogen gas, the residue was dissolved in $50 \mu \mathrm{l}$ methanol and injected into the HPLC-PDA.

Table 1 Quantitative results of morphine, codeine and methadone in spiked postmortem urine samples by DLLMEHPLC-PDA

\begin{tabular}{lllll}
\hline Analyte & Linearity & $\mathrm{R}^{2}$ & $\operatorname{LOD}\left(\mu \mathrm{gl}^{-1}\right)$ & $\mathrm{LOQ}\left(\mu \mathrm{g} \mathrm{I}^{-1}\right)$ \\
\hline Morphine & $\mathrm{y}=22,063 \mathrm{x}+1135.8$ & 0.9991 & 25 & 100 \\
Codeine & $\mathrm{y}=669,350 x-217,207$ & 0.9995 & 9 & 30 \\
Methadone & $\mathrm{y}=892,444 x-50,709$ & 0.9989 & 10 & 35.5 \\
\hline
\end{tabular}

Extraction condition: sample volume, $5 \mathrm{ml}, \mathrm{pH}=9.8$, volume of acetone as disperser solvent: $500 \mu \mathrm{l}$; volume of chloroform as extraction solvent: $300 \mu \mathrm{l}$ and extraction time of $0.5 \mathrm{~min}$

LOD (Limit of detection) for an $\mathrm{S} / \mathrm{N}=3$

LOQ (Limit of quantification) for an $S / N=10$

\section{Optimization of DLLME}

Affecting factors the DLLME procedure including the type and volume of extraction solvent, type and volume of disperser solvent, $\mathrm{pH}$ and extraction time were optimized in this study. Optimization of these factors was done by using postmortem blank urine samples spiked with morphine, codeine, and methadone.

\section{Validation of DLLME- HPLC-PDA method Limit of detection (LOD), limit of quantification (LOQ) and linearity}

The limit of detection (LOD) and the limit of quantification (LOQ) were considered as the lowest concentration of the analytes corresponding to relationship of signal to noise ratio 3:1 and 10:1, respectively (SWGTOX 2013). The linearity of the method determined in the concentration ranges of $0.5-100 \mu \mathrm{g} \mathrm{ml}^{-1}$ of morphine, codeine, and methadone. The calibration curves were drawn for morphine, codeine and methadone into blank postmortem urine samples spiked with concentrations of $0.5,2,5,10$, $20,30,40,50$ and $100 \mu \mathrm{g} \mathrm{ml}^{-1}$ for each analyte. All concentrations were analyzed in triplicate.

\section{Precision, accuracy, enrichment factor, recovery, and relative recovery}

Inter-day and intra-day precisions method, and the enrichment factors and recovery for morphine, codeine and methadone were studied by extracting the spiked blank postmortem urine samples with 2,10 and $30 \mu \mathrm{g} \mathrm{ml}^{-1}$ concentrations. In order to evaluate the accuracy of the method acting to prepare three urine samples with concentrations of 2,10 and $30 \mu \mathrm{g} \mathrm{ml}^{-1}$ of morphine, codeine, and 
Table 2 Validation parameters of analytes in postmortem urine samples

\begin{tabular}{|c|c|c|c|c|c|c|}
\hline Analyte & $\begin{array}{l}\text { Added concentration } \\
\left(\mu \mathrm{gml}^{-1}\right)\end{array}$ & $\begin{array}{l}\text { Intraday precision } \\
\text { RSD (\%) } \\
(n=3)\end{array}$ & $\begin{array}{l}\text { Interday precision } \\
\text { RSD }(\%) \\
(n=3)\end{array}$ & $\begin{array}{l}\text { Accuracy (Relative } \\
\text { Error \%) } \\
(\mathrm{SD}, n=3)\end{array}$ & $\begin{array}{l}\text { Recovery (\%) } \\
(\mathrm{SD}, n=3)\end{array}$ & $\mathrm{EF}$ \\
\hline \multirow[t]{3}{*}{ Morphine } & 2 & 4.1 & 2.8 & $-4.5(0.12)$ & $95.5(0.05)$ & 191 \\
\hline & 10 & 1.63 & 3.04 & $-2.7(0.09)$ & $107.9(0.28)$ & 215.8 \\
\hline & 30 & 5.6 & 4.05 & $-2.6(0.23)$ & $101.87(0.04)$ & 203.74 \\
\hline \multirow[t]{3}{*}{ Codeine } & 2 & 3.8 & 4.1 & $-51(0.23)$ & $87.5(0.09)$ & 175 \\
\hline & 10 & 3.9 & 6.07 & $-2.3(0.37)$ & $93.5(0.4)$ & 187 \\
\hline & 30 & 3.8 & 1.17 & $3.9(1.11)$ & $101.5(0.83)$ & 203 \\
\hline \multirow[t]{3}{*}{ Methadone } & 2 & 4.9 & 4.4 & $-8(0.1)$ & $89.5(0.14)$ & 179 \\
\hline & 10 & 5.7 & 5.7 & $1.7(0.26)$ & $97(0.12)$ & 194 \\
\hline & 30 & 3.4 & 3.6 & $-4.8(0.44)$ & $98.6(0.73)$ & 197.2 \\
\hline
\end{tabular}

Extraction condition: Sample volume, $5 \mathrm{ml}, \mathrm{pH}$ 9.8, volume of acetone as disperser solvent: $500 \mu$ l; volume of chloroform as extraction solvent: $300 \mu \mathrm{l}$ and extraction time: $0.5 \mathrm{~min}$ EF Enrichment Factor

methadone (control urine samples). Then each of the three control samples was divided into three equal parts and was extracted by DLLME process. Accuracy in the format of the relative error (RE\%) and precision to form of the relative standard deviation (RSD $\%)$ were reported.

The enrichment factor (EF) is the analytes concentration in the sediment and initial concentration of analytes within the sample and calculated according to previous study (Rezaee et al. 2006).
The extraction recovery (\%ER) was defined as the ratio between the amount of the analyte in the sediment and the initial amount of the analyte within the sample and determined as previous method (Rezaee et al. 2006).

The relative recovery was studied by extracting the spiked postmortem urine samples (with suspected drug abuse) with two concentrations of morphine, codeine, and methadone $\left(5\right.$ and $20 \mu \mathrm{g} \mathrm{ml}^{-1}$ ). And then the relative recovery (\%RR) was calculated according to the previous method (Rezaee et al. 2006).

Table 3 Relative recoveries and standard deviations of opioids in actual postmortem urine samples

\begin{tabular}{|c|c|c|c|c|c|}
\hline Analyte & Sample number & $\begin{array}{l}\text { Concentration of } \\
\text { analyte }\left(\mu \mathrm{g} \mathrm{m}^{-1}\right)\end{array}$ & $\begin{array}{l}\text { Added concentration } \\
\left(\mu \mathrm{g} \mathrm{m}^{-1}\right)\end{array}$ & $\begin{array}{l}\text { Founded } \\
\text { concentration }\left(\mu \mathrm{g} \mathrm{ml}^{-1}\right) \\
N=3 \text { (SD) }\end{array}$ & Relative recovery \\
\hline \multirow[t]{6}{*}{ Morphine } & 1 & 2.5 & 5 & $7.5(1.05)$ & 100 \\
\hline & & & 20 & 23.6 (1.19) & 105.5 \\
\hline & 2 & 17.8 & 5 & $21.4(0.84)$ & 88 \\
\hline & & & 20 & $38.4(1.57)$ & 103 \\
\hline & 3 & 8.7 & 5 & $13.5(0.41)$ & 96 \\
\hline & & & 20 & $26.1(0.77)$ & 87 \\
\hline \multirow[t]{6}{*}{ Codeine } & 1 & 2.2 & 5 & $7.12(0.03)$ & 98.4 \\
\hline & & & 20 & $21.05(0.53)$ & 94.3 \\
\hline & 2 & 5.3 & 5 & $9.98(0.36)$ & 93.6 \\
\hline & & & 20 & $27.24(1.84)$ & 109.7 \\
\hline & 3 & 0.9 & 5 & $5.34(0.62)$ & 88.8 \\
\hline & & & 20 & $17.76(1.10)$ & 84.3 \\
\hline \multirow[t]{6}{*}{ Methadone } & 1 & 1.9 & 5 & $5.96(1.09)$ & 82 \\
\hline & & & 20 & $23.70(1.31)$ & 109 \\
\hline & 2 & 3.2 & 5 & $8.35(1.2)$ & 103 \\
\hline & & & 20 & $24.76(1.29)$ & 107.8 \\
\hline & 3 & 10.4 & 5 & $14.87(0.57)$ & 89.4 \\
\hline & & & 20 & $28.79(0.12)$ & 91.95 \\
\hline
\end{tabular}




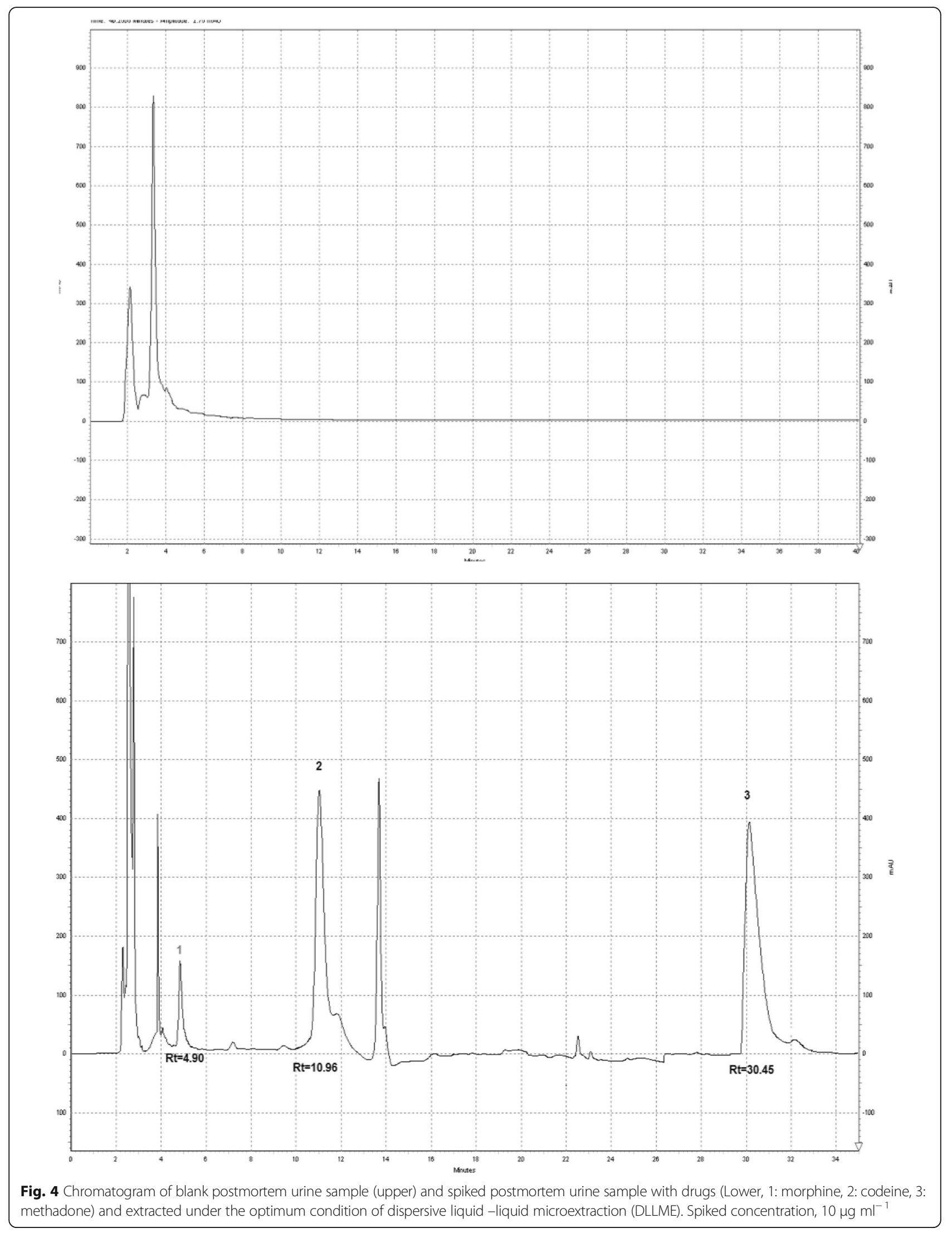




\section{Results and discussion}

\section{Selection of extraction solvent}

Selection of a suitable extraction solvent is one of the key steps in the DLLME procedure that direct impact on the efficiency of method (Rezaee et al. 2006). The extraction solvent should be have a characteristics such as higher density and low solubility in water, miscible with disperser solvent and capability for extraction of target analytes (Saraji and Boroujeni 2014; Sharifi et al. 2016). Chloroform due to have characteristics such as the higher density than water, the boiling point and the solubility in water, was used as appropriate extraction solvent to extract opioids from the postmortem urine samples (Shamsipur and Fattahi 2011).

\section{Selection of disperser solvent}

The disperser solvent should be miscible in the water and dissolve in the extraction solvent and capable to form a cloudy solution (Saraji and Boroujeni 2014; Sharifi et al. 2016). In this study, acetone was selected as dispersive solvent due to the highest recovery of opium alkaloids, lower toxicity and cheaper than methanol and acetonitrile.

\section{Optimization of extraction solvent volume}

The effect of extraction solvent volume in the recovery of morphine, codeine and methadone in postmortem urine samples in the DLLME process, was investigated using different volumes of chloroform (88, 100, 150, 200, 300 and $350 \mu \mathrm{l})$. All concentrations were analyzed in triplicate. With increase the volume of chloroform from 88 to $350 \mu \mathrm{l}$, increased the volume of the sediment phase. With the increasing volume of chloroform from 88 to $300 \mu \mathrm{l}$, for each analyte, extraction efficiency were increased, while a further increase in the volume of chloroform (higher than $300 \mu \mathrm{l}$ ) were given a small reduction in extraction efficiency and a reduction in the enrichment factor of these three compounds. At low volumes of chloroform (88 and $100 \mu \mathrm{l}) \mathrm{a}$ significant reduction in analyte extraction efficiency were observed. Therefore, based on the results, $300 \mu \mathrm{l}$ was selected as the optimal volume of extraction solvent (Fig. 1).

\section{Optimization of disperser solvent volume}

Performance of DLLME method directly influences by the volume of dispersive solvent. Changes in the volume of dispersive solvent cause changes the volume of the sediment phase. To obtain an optimal volume of acetone, was performed by several experiments using different volumes of acetone contains (300, 500, 750, 1000, 1500 and $2000 \mu \mathrm{l})$ and various volumes of chloroform (88, 100, 150, 200, 300 and $350 \mu \mathrm{l})$. All concentrations were analyzed in triplicate. The results showed that at low volume of acetone $(300 \mu \mathrm{l})$ dispersion of the chloroform did not complete and a decrease in extraction recovery was observed. Also, in the high volume of acetone (1500 and $2000 \mu \mathrm{l})$, extraction recovery of morphine, codeine, and methadone decreased due to the increased solubility of the analyte in the sample solution and reducing entry them into the organic phase. Therefore, based on the results, $500 \mu \mathrm{l}$ of acetone was selected as the optimal volume of disperser solvent in this study.

\section{Optimization of $\mathrm{pH}$}

Addition of adequate amount of sodium carbonate to the sample solutions, in order to adjust the $\mathrm{pH}$ and ionic strength of solutions, directly effect of the extraction efficiency. In this study, the extraction recovery of morphine, codeine, and methadone was examined in different $\mathrm{pH}$ in the range of 8.5-11.5 (an average of 8.7, 9.8, 10.5 and 11.3). The results obtained showed that very low $\mathrm{pH}$ in the range of 8.5-9 (average 8.7) and as well as in high $\mathrm{pH}$ in the range of 11-11.5 (average 11.3), extraction efficiency for all three compounds in the study, significantly decreased. Also, in the $\mathrm{pH} 10-11$ (average 10.5) is a very small reduction in the extraction efficiency. So, with the view of increasing the extraction efficiency of morphine, codeine, and methadone in the $\mathrm{pH}$ 9.8, this $\mathrm{pH}$ was selected as optimum for extraction of the opioids from postmortem urine samples (Fig. 2).

\section{Optimization of extraction time}

Optimization of extraction time in a variety of liquidphase microextraction, is a critical factor that plays a great impact on the extraction efficiency. In DLLME method, the extraction time is defined as the interval time between fast injecting a mixture of extraction and dispersive solvents into the sample solution before the start of centrifuges (Rezaee et al. 2006; Shamsipur and Fattahi 2011). In this study, the effect of extraction time on the enrichment factor and extraction efficiency was determined. A range time from 0 to $15 \mathrm{~min}(0,0.5,2,8$ and $15 \mathrm{~min}$ ) were evaluated. The results showed that extraction time has no significant effect on the extraction recovery for morphine, codeine and methadone. Thus the extraction time in all experiments carried out in this study was $30 \mathrm{~s}$ (Fig. 3).

\section{Validation of method}

The characteristics of the calibration curves were summarized in Table 1. All results were obtained under the optimized conditions and repeated in triplicate. The calibration curves were linear over the concentration ranges of $0.5-100 \mu \mathrm{g} \mathrm{ml}^{-1}$ for morphine, codeine, and methadone. The values of the correlation coefficients $\left(R^{2}\right)$ ranged from 0.9989 to 0.9995 . Inter-day and Intra-day precision results that were studied by extracting the spiked samples with 2,10 and $30 \mu \mathrm{g} \mathrm{ml}^{-1}$ of morphine, 
Table 4 Comparison of DLLME-HPLC-PDA with other analytical methods for determination of morphine, codeine and methadone in biological samples

\begin{tabular}{|c|c|c|c|c|c|c|c|}
\hline Method & Sample & Analyte & $\operatorname{LOD}\left(\mu \mathrm{I} \mathrm{I}^{-1}\right)$ & \%RSD & Recovery (\%) & Extraction Time(min) & Author \\
\hline \multirow[t]{2}{*}{ SPE-FLC/DAD } & Urine & Morphine & 7.6 & 5.5 & 72.83 & $>40$ & Dams et al. 2002 \\
\hline & Blood & Codeine & 6.3 & 5.4 & 85.39 & & \\
\hline \multirow[t]{2}{*}{ SPE-HPLC/DAD } & Plasma & Morphine & 24 & 4.02 & & $>20$ & Fernandez et al. 2006 \\
\hline & & Codeine & 32 & 3.18 & - & & \\
\hline \multirow[t]{2}{*}{ DLLME - SFO -HPLC-UV } & Plasma & Morphine & 5 & 7.4 & 55.2 & 0.5 & Leong and Huang 2008 \\
\hline & & Codeine & 5 & 6.5 & 66.3 & & \\
\hline \multirow[t]{2}{*}{ DLLME -HPLC-UV } & Urine & Morphine & 7 & 6.1 & 31.5 & 4 & Shamsipur and Fattahi 2011 \\
\hline & & Codeine & 10 & 5.7 & 42.7 & & \\
\hline DLLME -HPLC-UV & $\begin{array}{l}\text { Urine } \\
\text { Plasma }\end{array}$ & Methadone & 4.9 & 2.26 & 100.34 & 3 & Ranjbari et al. 2012 \\
\hline \multirow[t]{2}{*}{ DLLME-CE-ESI-TOF-MS } & Urine & Codeine & 0.5 & 74 & 74 & - & Kohler et al. 2013 \\
\hline & & Methadone & 0.25 & - & 90 & & \\
\hline \multirow[t]{2}{*}{ DLLME - HPLC-PDA } & Plasma & Morphine & 28.5 & 3 & $>84$ & 3.5 & Fernández et al. 2013 \\
\hline & & Methadone & 13.9 & 1.2 & & & \\
\hline DLLME-UA-LDS- GC/MS & Urine & Methadone & 1.5 & 4.7 & 86.5 & 3 & Meng et al. 2015 \\
\hline \multirow[t]{3}{*}{ DLLME - HPLC-PDA } & Urine & Morphine & 25 & 3.04 & 101.87 & 0.5 & Present Study \\
\hline & & Codeine & 9 & 3.8 & 93.5 & & \\
\hline & & Methadone & 10 & 4.4 & 98.6 & & \\
\hline
\end{tabular}

LOD Limit of detection, RSD Relative standard deviation

codeine, and methadone, was reported (Table 2). Also, the accuracy of the method was evaluated by calculating of relative error. Relative error is not more than $\% \pm 15$. In this study, the relative error for morphine, codeine and methadone in the ranges of -8 to $3.9 \%$ was obtained (Table 2). LOD and LOQ for all the analytes were in the ranges of $9-25 \mu \mathrm{gl}^{-1}$ and $30-100 \mu \mathrm{gl}^{-1}$, respectively (Table 1). The enrichment factor, recovery and relative recovery for morphine, codeine and methadone, was calculated and showed in the tables (Tables 2 and 3).

The simplest method for evaluation of selectivity of an analytical method is checking of absence of response in blank samples. There were no interferences at the retention times of three target analytes in the method (Fig. 4).

\section{Application of DLLME-HPLC-PDA procedure}

After the optimization of the effective factors on DLLME and achieving to good and satisfactory results from the validated method, the DLLME-HPLC-PDA was used successfully for extraction and determination of morphine, codeine, methadone in 50 actual postmortem urine samples. Based on the obtained results, morphine was found in 22 samples, codeine was detected in 17 samples and methadone was detected in 27 samples. Some of the opium alkaloids such as papaverine, thebaine and noscapine were identified at 2, 1 and 3 samples, respectively. Also, 6monoacetylmorphine and tramadol were determined in 8 and 6 samples, respectively. Concentration of morphine, codeine and methadone in postmortem urine samples were calculated in the range of: $0.28-26 \mu \mathrm{g} \mathrm{ml} \mathrm{ml}^{-1}$ (mean: $6.7 \mu \mathrm{g} \mathrm{ml}{ }^{-1}$ ) for morphine, 0.9-25.4 $\mu \mathrm{g} \mathrm{ml} \mathrm{m}^{-1}$ (mean: $13.52 \mu \mathrm{g} \mathrm{ml}^{-1}$ ) for codeine and $0.4-43.8 \mu \mathrm{g} \mathrm{ml}^{-1}$ (mean: $33.5 \mu \mathrm{g} \mathrm{ml}^{-1}$ ) for methadone.

\section{Comparison of DLLME-HPLC-PDA method with other methods}

Table 4 summarized the comparison of the proposed method for the determination of morphine, codeine, and methadone in postmortem urine samples by the DLLME-HPLC-PDA with previous methods such as SPE-HPLC-DAD, SPE-FLCDAD, DLLME-GC-MS, DLLME-SFO-HPLC and DLLMEHPLC-UV. The recovery and extraction time of the present method is better than other methods (Table 4). LOD in the proposed method is similar to the previous studies (Dams et al. 2002; Leong and Huang 2008; Shamsipur and Fattahi 2011; Ranjbari et al. 2012; Kohler et al. 2013; Fernández et al. 2013; Meng et al. 2015) (Table 4).

\section{Conclusion}

In this study, the efficiency and performance of DLLME process were assessed under optimum conditions for the extraction of opioids from postmortem urine samples. According to repeatability, linearity, high extraction efficiency and good enrichment factor, this method is 
suitable for qualitative and quantitative analysis of opioids in postmortem urine samples. This is the first DLLME-HPLC-PDA method which optimized for postmortem urine samples and should be considered as an applied analytical method for determination of opioids in forensic toxicology laboratory.

\section{Acknowledgements}

We would like to show our gratitude to the Legal Medicine Research Center, Legal Medicine Organization, Tehran- Iran for financial support of this study.

\section{Funding}

This research was supported by Legal Medicine Research Center, Legal Medicine Organization, Tehran- Iran (Grant No. 20726).

\section{Availability of data and materials}

Not applicable

\section{Authors' contributions}

EA attributed in method validation, analysis of samples, data gathering and analysis and writing of the draft of the manuscript. MS attributed in sample collection and data gathering. AS attributed in method validation and analysis of the samples. GR attributed method validation and data gathering. KS attributed in study design, supervision on all of the research's steps, revision the draft and writing the final version. All authors approved the final version of the paper.

\section{Authors' information}

EA (MSc in Toxicology) works as a technical expert in Laboratory of Toxicology. MS (MD, Forensic Medicine specialist) is head of the Zanjan Legal Medicine Center, Zanjan, Iran and member of the Legal Medicine Research Center, Legal Medicine Organization, Tehran Iran.AS (MSC in Toxicology) and GR (BS) are work as technical experts in Forensic Toxicology Laboratory of Zanjan Legal Medicine Center, KS (PharmD, PhD in Toxicology) is Associate Professor of Toxicology, Department of Forensic Toxicology, Legal Medicine Research Center, Legal Medicine Organization, Tehran Iran.

\section{Ethics approval and consent to participate}

All procedures performed in study involving human participants were in accordance with the ethical standards of the Legal Medicine Research Center's ethical committee (Grant No. 20726) and with the 1964 Helsinki declaration and its later amendments or comparable ethical standards.

\section{Consent for publication}

Not applicable

\section{Competing interests}

The authors declare that they have no competing interest.

\section{Publisher's Note}

Springer Nature remains neutral with regard to jurisdictional claims in published maps and institutional affiliations.

\section{Author details}

'Department of Pharmacology and Toxicology, Faculty of Pharmacy, Pharmaceutical Sciences Branch, Islamic Azad University (IAUPS), Tehran, Iran ${ }^{2}$ Legal Medicine Center of Zanjan Province, Zanjan, Iran. ${ }^{3}$ Department of Forensic Toxicology, Legal Medicine Research Center, Legal Medicine Organization, Tehran 1114795113, Iran

Received: 30 August 2017 Accepted: 23 January 2018 Published online: 02 February 2018

\section{References}

Ahmadi-Jouibari T, Fattahi N, Shamsipur M, Pirsaheb M (2013) Dispersive liquidliquid microextraction followed by high-performance liquid chromatography-ultraviolet detection to determination of opium alkaloids in human plasma. J Pharm Biomed Anal 85:14-20
Cheng J, Matsadiq G, Liu L, Zhou YW, Chen G (2011) Development of a model ultrasound-assisted surfactant-enhanced emulsification microextraction method and its application to the analysis of eleven polycyclic aromatic hydrocarbons at trace levels in water. J Chromatography A 1218:2476-2482

Dams R, Benijts T, Lambert WE, De Leenheer AP (2002) Simultaneous determination of in total 17 opium alkaloids and opioids in blood and urine by fast liquid chromatography-diode-array detection-fluorescence detection, after solid-phase extraction. J Chromatography B 773:53-61

Drummer OH (2004) Postmortem toxicology of drugs of abuse. Forensic Sci Int 42:101-113

Fernandez P, Morales L, Vazquez C, Bermejo AM, Tabernero MJ (2006) HPLC-DAD determination of opioids, cocaine and their metabolites in plasma. Forensic Sci Int 161:31-35

Fernández P, González C, Pena MT, Carro AM, Lorenzo RA (2013) A rapid ultrasound-assisted dispersive liquid-liquid microextraction followed by ultraperformance liquid chromatography for the simultaneous determination of seven benzodiazepines in human plasma samples. Anal Chim Acta 767:88-96

Fernández P, Regenjo M, Bermejo A, Fernández A, Lorenzo R, Carro A (2015) Analysis of drugs of abuse in human plasma by dispersive liquid-liquid microextraction and high performance liquid chromatography. J Applied Toxicol 35(4):418-425

Gergov M, Nokua P, Vuori E, Ojanpera I (2009) Simultaneous screening and quantification of 25 opioid drugs in post-mortem blood and urine by liquid chromatography-tandem mass spectrometry. Forensic Sci Int 186:36-43

He Y, Lee HK (1997) Liquid-phase microextraction in a single drop of organic solvent by using a conventional microsyringe. Anal Chem 69:4634-4640

Jeannot MA, Cantwell FF (1996) Solvent microextraction into a single drop. Anal Chem 68:2236-2240

Kohler I, Schappler J, Sierro T, Rudaz S (2013) Dispersive liquid-liquid microextraction combined with capillary electrophoresis and time-of-flight mass spectrometry for urine analysis. J Pharm Biomed Anal 73:82-89

Lee J, Lee HK, Rasmussen KE, Pedersen-Bjergaard S (2008) Environmental and bioanalytical applications of hollow fiber membrane liquid-phase microextraction: a review. Anal Chim Acta 624:253-268

Leong M, Huang SD (2008) Dispersive liquid-liquid microextraction method based on solidification of floating organic drop combined with gas chromatography with electron-capture or mass spectrometry detection. J Chromatography A 1211:8-12

Li Y, Hu J, Liu X, Fu L, Zhang X, Wang X (2008) Dispersive liquid-liquid microextraction followed by reversed phase HPLC for the determination of decabrominated diphenyl ether in natural water. J Sep Sci 31:2371-2376

Ma JJ, Du X, Zhang JW, Wang LZ (2009) Ultrasound-assisted emulsification microextraction combined with flame atomic absorption spectrometry for determination of trace cadmium in water samples. Talanta 80:980-984

Mabuchi M, Takatsuka S, Matsuoka M, Tagawa K (2004) Determination of morphine, morphine-3-glucuronide and morphine-6-glucuronide in monkey and dog plasma by high-performance liquid chromatography-electrospray ioniza- tion tandem mass spectrometry. J Pharm Biomed Anal 35:563-573

Mashayekhi HA, Abroomand-Azar P, Saber-Tehrani M, Hussain SW (2010) Rapid determination of carbamazepine in human urine, plasma samples and water using DLLME followed by RP-LC. Chromatographia 71:517-521

Meng L, Zhang W, Meng P, Zhu B, Zheng K (2015) Comparison of hollow fiber liquid -phase microextraction andultrasound-assisted low-density solvent dispersive liquid-liquid microextraction for the determination of drugs of abuse in biological samples by gas chromatography-mass spectrometry. J Chromatography B 989:46-53

Nagaraju D, Huang SD (2007) Determination of triazine herbicides in aqueous samples by dispersive liquid-liquid microextraction with gas chromatographyion trap mass spectrometry. J Chromatography A 1161:89-97

Pathan H, Williams J (2012) Basic opioid pharmacology: an update. Br J Pain 6(1):11-16

Ranjbari E, Golbabanezhad-Azizi AA, Hadjmohammadi MR (2012) Preconcentration of trace amounts of methadone in human urine, plasma, saliva and sweat samples using dispersive liquid-liquid microextraction followed by high performance liquid chromatography. Talanta 94:116-122

Rezaee M, Assadi Y, Hosseini MRM, Aghaee E, Ahmadia F, Berijani S (2006) Determination of organic compounds in water using dispersive liquid-liquid microextraction. J Chromatography A 1116:1-9

Rezaee M, Yamini Y, Faraji M (2010a) Evolution of dispersive liquid-liquid microextraction method. J Chromatography A 1217:2342-2357

Rezaee M, Yamini Y, Hojjati M, Faraju M (2010b) Novel extraction method based on the dispersión of the extraction solvent for extraction of letrozole from biological fluids. Anal Methods 2:1341-1345 
Saraji M, Boroujeni MK (2014) Recent developments in dispersive liquid-liquid microextraction. Anal Bioanal Chem 406(8):2027-2066

Saraji M, Khalili Boroujeni M, Hajialiakbari Bidgoli AA (2011) Comparison of dispersive liquid-liquid microextraction and hollow fiber liquid-liquid-liquid microextraction for the determination of fentanyl, alfentanil, and sufentanil in water and biological fluids by high-performance liquid chromatography. Anal Bioanal Chem 400:2149-2158

Shamsipur M, Fattahi N (2011) Extraction and determination of opium alkaloids in urine samples using dispersive liquid-liquid microextraction followed by highperformance liquid chromatography. J Chromatography B 879(28):2978-2983

Sharifi V, Abbasi A, Nosrati A (2016) Application of hallow fiber liquid phase microextraction and dispersive liquid-liquid microextraction techniques in analytical toxicology. J Food Drug Anal 24:264-276

Shen G, Lee HK (2002) Hollow fiber-protected liquid-phase microextraction of triazine herbicides. Anal Chem 74:648-654

SWGTOX (2013) Scientific working Group for Forensic Toxicology (SWGTOX) standard practices for method validation in forensic toxicology. 2013. Available from: https://academic.oup.com/jat/articlepdf/37/7/452/2299550/ bkt054.pdf, 11 Oct 2017

UNODC (2016) World drug report 2016. United Nations publications, New York Wey AB, Thorman W (2001) Capillary electrophoresis-electrospray ionization ion trap mass spectrometry for analysis and confirmation testing of morphine and related compounds in urine. J Chromatography A 916:225-238

Whittington D, Kharasch ED (2003) Determination of morphine and morphine glucuronides in human plasma by 96-well plate solid-phase extraction and liquid chromatography-electrospray ionization mass spectrometry. J Chromatography B 796:95-103

Xiong C, Ruan J, Cai Y, Tang Y (2009) Extraction and determination of some psychotropic drugs in urine samples using dispersive liquid- liquid microextraction followed by high-performance liquid chromatography. J Pharm Biomed Anal 49:572-578

Yan H, Wang H (2013) Recent development and applications of dispersive liquidliquid microextraction. J Chromatography A 1295:1-15

Zhang Y, Lee HK (2012) Application of ultrasound-assisted emulsification microextraction based on applying low-density organic solvent for the determination of organochlorine pesticides in water samples. J

Chromatography A 1252:67-73

\section{Submit your manuscript to a SpringerOpen ${ }^{\circ}$} journal and benefit from:

- Convenient online submission

- Rigorous peer review

- Open access: articles freely available online

- High visibility within the field

- Retaining the copyright to your article

Submit your next manuscript at $>$ springeropen.com 